Journal of Electrical Engineering and Automation (EEA) (2020)

Vol.02/ No. 02

Pages: 92-101

https://www.irojournals.com/iroeea

DOI: https://doi.org/10.36548/jeea.2020.2.005

\title{
Performance Analysis of Multiple Pico Hydro Power Generation
}

\author{
Dr. P. Karrupusamy, \\ Professor, Department of Electronic and Communication Engineering, \\ Shree Venkateshwara Hi-Tech Engineering College, India. \\ Email id: pkarrupusamyphd@gmail.com
}

\begin{abstract}
Electric energy has become a basic and essential thing in human life. The electricity is not only utilized for entertainment, it also helpful in powering many devices utilized in medicine, emergency and assisting. Generation of electric power is not a simple task in any medium. There are several medium of power generation is possible in the present scenario. At present, renewable source of energy generation has become popular because of its atmosphere friendly nature and reduced cost of installation for generating station. Hydro power generation is one among such method of power generation produces electricity by means of rotating a turbine blades with running water. The traditional hydro power plants were made to produce electric energy from the river water movement and falls water movement. The proposed MPH (Multiple Pico Hydro) power generation scheme is developed to make power generation from the domestic running water flowing in the pipeline of a home or apartment. The produced power is stored to a battery source and inverted in to an alternating current supply for powering the home. To make an efficient model the pico power generators are fixed to multiple pipelines. The performance of the proposed model is analyzed and it can be connected to another renewable energy sources for making a hybrid structure of power generation.
\end{abstract}

Keyword: Pico hydro generator, domestic power generation, micro power generation.

\section{Introduction}

Generation of electricity from renewable energy sources are usually produce DC (Direct Current) supply as output. So that the generated energy can be stored in a battery source for later operations. The energy produced with AC (Alternating Current) generator cannot be stored at any point of time but the advantage of the AC supply is modulation. The produced electric energy from DC generator can be transmitted to very long distance when it is converted in to AC supply. The property of AC supply has the ability to transmit the supply for very long distance with lesser line loss. Where as in DC supply the loss is very high in nature. The limitation of DC supply was attained in AC supply by stepping up the produced voltage in to higher range for transmission. This is achieved by placing step-up transformers in the transmission line. The step-upped voltages are step-downed at the end user location with the help of step-down transformers for smooth transmission.

ISSN: 2582-3051 
Journal of Electrical Engineering and Automation (EEA) (2020)

Vol.02/ No. 02

Pages: 92-101

https://www.irojournals.com/iroeea

DOI: https://doi.org/10.36548/jeea.2020.2.005

In domestic renewable energy generation for lesser load applications, the produced energy is need not to be transmitted for very long distance. Hence there is no need of transformers for stepping up and stepping down the voltages. But the challenge in renewable energy generation is that the energy production takes place only when the primary energy for rotating the generator is available. The primary energy for hydro power generation is water flow. Water flow at residential area never takes place continuously all the time. So that a battery source is generally added to save the produced energy for later usage. Figure 1 explores the general flow of DC power generation. The driver in the block indicates the primary source needed to rotate the turbine for DC generation. The DC power generated is transmitted to the end user through an inverter unit for energy conversion from DC to AC. A DC storage unit is kept over DC output and inverter unit for saving the unused energy for later purpose. The energy stored in the DC storage can be taken later when there is no primary source is available for power generation.

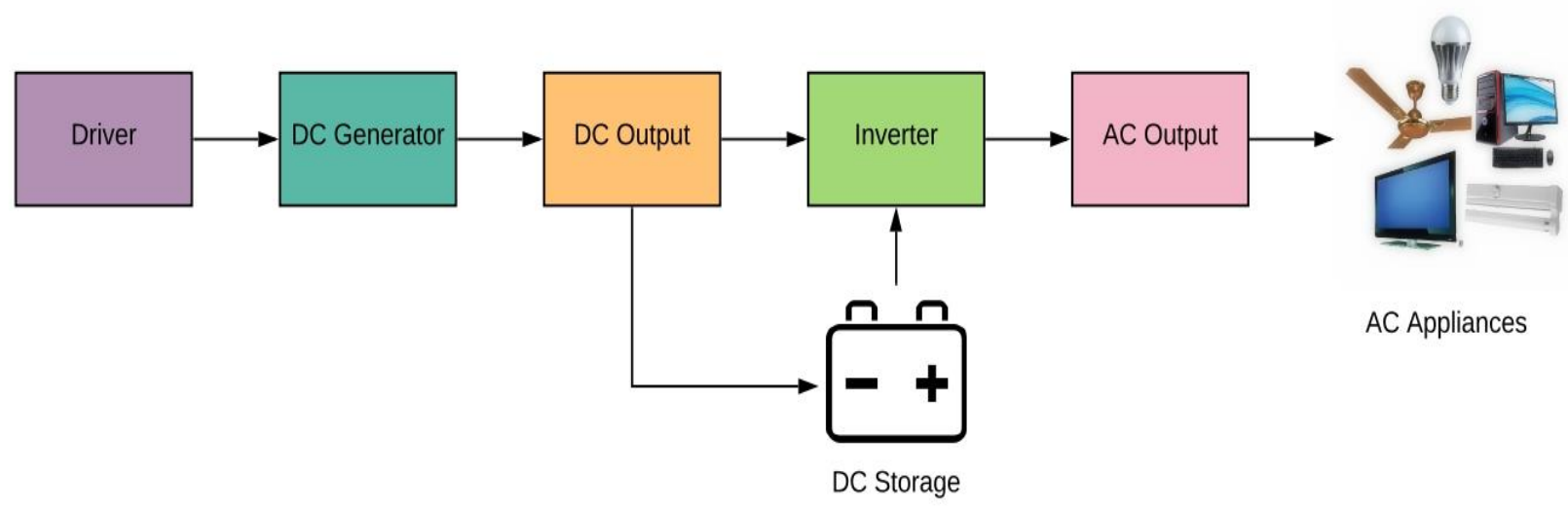

Figure 1. DC Power Generation and Transmission.

The DC power produced by a generator cannot be directly used for any purpose as it produces unregulated voltage, it may contain ripples and surges on the power and it may cause serious damages to the circuit present in the appliances. These drawback is rectified by placing a control unit after the generator. Figure 2 indicates the components available in the control unit for operation. 
Journal of Electrical Engineering and Automation (EEA) (2020)

Vol.02/ No. 02

Pages: 92-101

https://www.irojournals.com/iroeea

DOI: https://doi.org/10.36548/jeea.2020.2.005

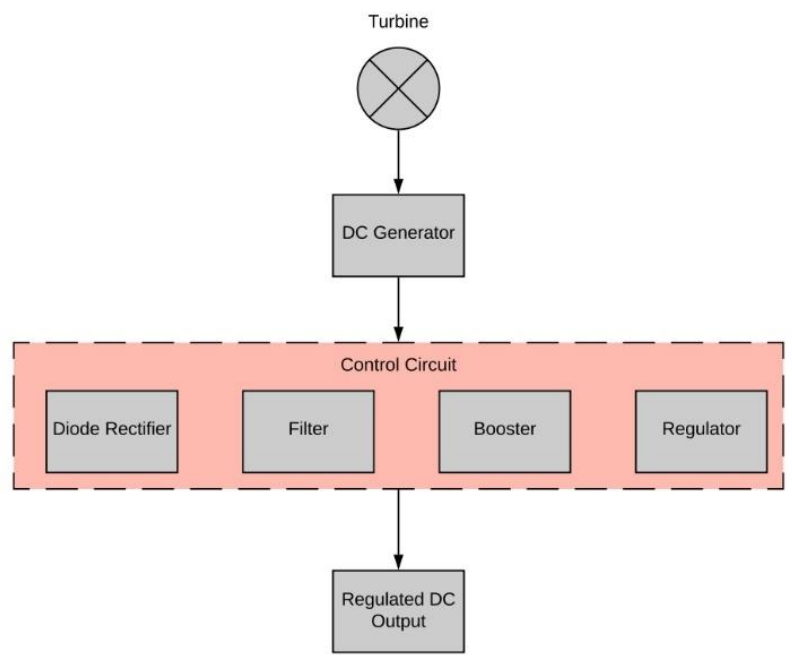

Figure 2. DC Supply Regulation Process.

The control unit consists of diode rectifier for making the produced voltage in to a DC voltage with uniform rectified DC output to avoid reverse voltages. A filter unit is employed to remove the micro ripples in the power generated for smoothing the voltage. The smoothed voltage is boosted to certain level with DC to DC booster for giving a higher voltage output than the produced voltage to meet up the requirements for charging the storage cells. The boosted voltage is regulated to particular level for charging the battery in constant mode. The control unit improves the reliability and efficiency of the DC power generation process.

\section{Related Work}

The cost minimization on installing the micro hydro power plant station [1] was discussed by analyzing the need of power requirement to the amount of power generated by a turbine. The turbine size is an important factor to be consider for power plant installation. A right specification of turbine produces efficient output in power generation. The cost of power generation is also depends on maintenance of turbines at idle position. The turbine selection does not depends upon only the power demand, it also depends upon the amount of water flowing in that particular area can be utilized for power generation. Importance of generating maximum power from a generating station [2] was analyzed in photo voltaic system by adding a fuzzy logic system. The system determines the minimum and maximum power generated by the unit for calculating its capability of generation. The fuzzy based system is compared with the traditional systems for performance analysis and the simulation result indicates that the proposed system did a better job in

ISSN: 2582-3051 
Journal of Electrical Engineering and Automation (EEA) (2020)

Vol.02/ No. 02

Pages: 92-101

https://www.irojournals.com/iroeea

DOI: https://doi.org/10.36548/jeea.2020.2.005

maximum power generation. The sustainability of the micro hydro power plant is assessed [3] in terms of measuring investment cost, load factor, capacity factor, grid design and quality of power. These parameter measurements were done in $26 \mathrm{KW}$ power hydro power plant for finding its efficiency in generating power from the water flow for verifying the suitability of the turbine. The evaluation is helpful in adding supporting tool for better improvement to the generating station.

An integer programming optimization design [4] for micro hydro powe plant was structured from the data observed from the river profile. The river profile is collected from a simple design of pelton wheels coupled with a generator unit for power generation. From the study parameters the model profile is made for hydro power plant design. This method of profile preparation is helpful in pre-estimation of water flow and identification of minimum power supply that can be generated. The performance of battery device has been improved by in mobile phones by calculating its computational loading [5]. So that the device battery has been separated for computational loading and other offloading purpose. These kind of splits improves the battery efficiency and life. Takagi-Sugeno fuzzy model prototype of three phase micro hydro power plant [6] was developed to perform several test of the power plant in various load and water flow conditions. The model is helpful in suggesting a turbine range and battery power for operations. The proposed model performs better than the traditional model analysis method.

Estimation model for micro hydro power plants in hybrid energy systems [7] were designed for performance evaluation of the system in different scenario. This model calculates the electro-mechanical estimation for installation, power generated and net usage of power generated by the system. The proposed model parameters close very nearer to the real time estimation of model prescription. A hybrid algorithm [8] for utilizing the stored energy from a battery cell is proposed for network data transmission purpose. The given energy is utilized without the power loss in the transmission is a necessary parameter for network transmission. Hence a specialized algorithm based on ant colony optimization and genetic algorithm is proposed to save the produced energy efficiently. A modified pump setup was made as turbine for power generation [9]. The experiment was carried out by giving water flow externally from other source of pump to the modified turbine for power generation. The output power generated from the modified pump system is analyzed with the power required to pump inside the turbine in two different scenarios. One time the experiment was taken with guide vane and another time without guide vane. The efficiency at without vane was around $22 \%$ and with guided vane the efficiency is improved to $38 \%$.

An electromechanical system was developed to control the micro hydro power plant [10] to meet the fluctuations in frequency changes. The electrical system of the developed model is made with ballast load to balance the load power when there is a need. The changes in load and water flow to turbine cause power fluctuations in the produced power. To overcome that the ballast load is added to the model. The mechanical part of the model is designed with sliding gate connected with DC motor for controlling the water flow in

ISSN: 2582-3051 
Journal of Electrical Engineering and Automation (EEA) (2020)

Vol.02/ No. 02

Pages: 92-101

https://www.irojournals.com/iroeea

DOI: https://doi.org/10.36548/jeea.2020.2.005

to the turbine. The model increases the efficiency of the micro hydro power plant both in real time model and MATLAB simulation model. A rechargeable battery system [11] was considered to supply power for medical implant devices. The charging system of the battery consists of transmitter coil at the outside of the device and a receiver coil implanted together with the implanted device. A high frequency of supply is transmitted from primary compensation circuit to the secondary compensation circuit through the coils and the receiver side compensation circuit is added with an AC to DC converter for charging the battery element. A pico hydro power generation system [12] from the flow of water in the pipeline of a multi-storage building was designed to minimize the energy demand of the building. An AC generator of $5 \mathrm{~W}$ capacity is fixed to the pipeline for converting the kinetic energy produced by the water flow in to an electrical energy. An electronic power converter is fixed to the generator for converting the AC supply in to DC supply for battery storage. The produced power is varied with respect to the amount of water flowing inside the turbine was analyzed for performance analysis. The power output can be increased when the number of blades in the turbine are modified for faster rotation.

A continuous power generation system [13] was developed by combining photovoltaic cell for pumping the water to the upward storage and a pico turbine for generating energy from the water flow from the storage tank back to the ground level. The system is well suitable for where the water is stagnant at the ground level for long hours. Water at ponds and wells can be utilized for these kind of power generation. The model is designed without battery storage, inverters and transformers for minimizing the cost and simple installation. The energy production can be changed or controlled by the valve fixed out to the storage container for modifying the amount of water to be flow through the turbine for power generation. An optimized route selection algorithm [14] was proposed to save the energy availability in the battery source. The amount of energy utilized for useful performance improves the efficiency of the system with respect to cost factors involved in the generating part. The efficiency of the pico hydro generating system can be identified by measuring the efficiency of the turbine and the alternator separately [15]. The frequency changes due to changes in flow of water is compensated by an electrical circuit installed to the system. The efficiency of the turbine gets changes when it is connected to the generating system.

\section{Proposed Work}

The proposed pico hydro power generation is equipped with multiple number of hydro generators for improving the current output for charging the battery source. Figure 3 shows a pico hydro generator fixed with half inch dimension of inlet and outlet portion for water movement to rotate the turbines connected to the generator. The turbine and generator parts are directly coupled to each other for energy generation. The generated energy can be directly taken through the wire which is already connected to the generator module. The pico generator produces nearly $20 \mathrm{~V}$ DC output of $150 \mathrm{~mA}$ current when the turbine inlet gets 2 liters of water per minute. The produced energy can be used to recharge any kind of $12 \mathrm{~V}$ and $5 \mathrm{~V}$ battery sources.

ISSN: 2582-3051 
Journal of Electrical Engineering and Automation (EEA) (2020)

Vol.02/ No. 02

Pages: 92-101

https://www.irojournals.com/iroeea

DOI: https://doi.org/10.36548/jeea.2020.2.005

The current range can be increased to desired range by connecting additional pico generators in parallel to the each generator.

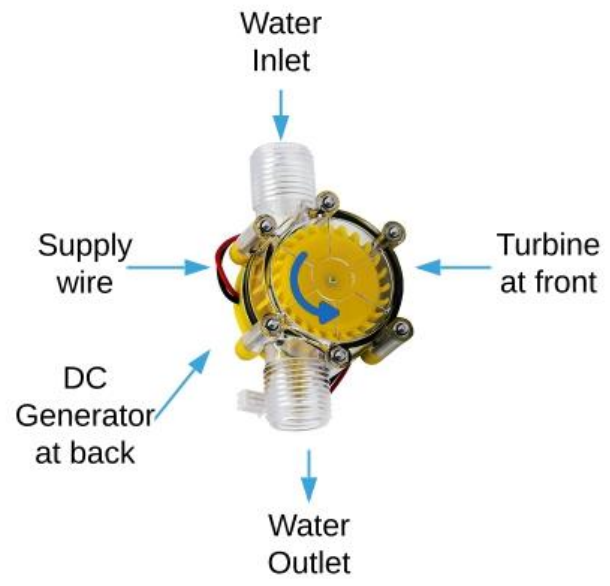

Figure 3. Pico Hydro Generator.

The parallel connected pico generators are fixed to a pipeline which works for long hours. The generators are fixed to the line where the water flows from upwards to downwards direction to avoid over load the water pump. The generator groups can also be connected to the pipeline without pump for generating power. The only condition for fixing the generator row is the water flow in the line must be running at least for certain hours to produce efficient energy. Figure 4 explores the blocks involved in the proposed MPH model. The wires from the generators are connected to the control circuit for transmitting it to the load and application fields. The control circuit comprises of rectifier circuit to avoid reversal current entering the circuit and a filter circuit is added with series to the rectifier for removing ripples in the produced supply. The filtered output is boosted to certain level for improving the current rating of the produced energy. The boosted supply is regulated by a regulator circuit for giving constant output to the applications. A battery source of $12 \mathrm{~V}, 2 \mathrm{Ah}$ is added to the model for saving the energy produced by the generators and an inverter circuit is made to convert the DC energy stored in the battery in to AC supply for applications. An arduino microcontroller is fixed to the process for monitoring water flow, turbine speed, and output energy for performance evaluation. 
Journal of Electrical Engineering and Automation (EEA) (2020)

Vol.02/ No. 02

Pages: 92-101

https://www.irojournals.com/iroeea

DOI: https://doi.org/10.36548/jeea.2020.2.005

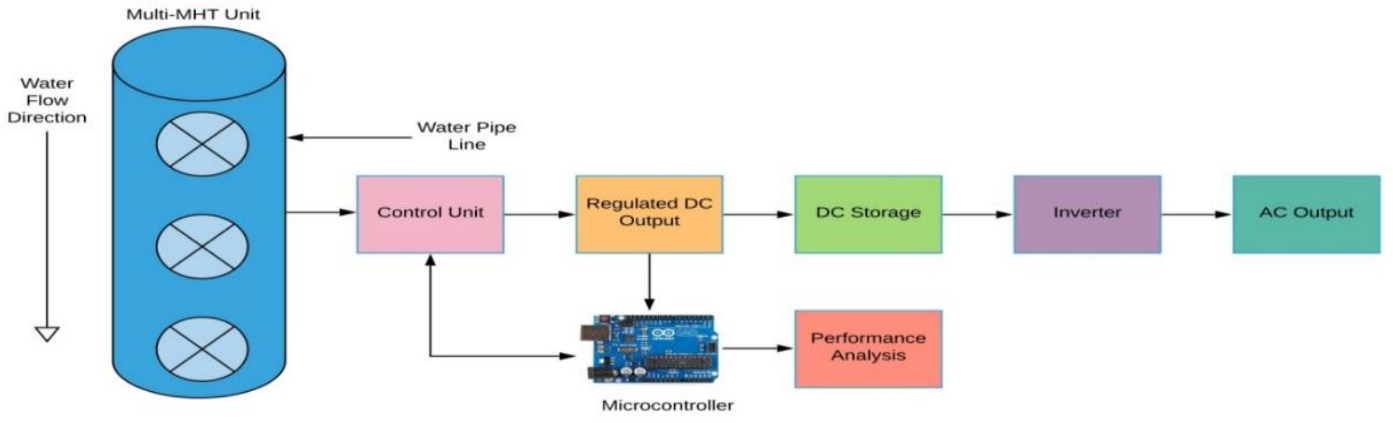

Figure 4. Proposed MPH Model Structure.

\section{Results and Discussion}

The performance of the proposed system is analyzed with respect to amount of energy generated with respect to amount of water flowing in to a generator. The analysis was performed separately for a single generator and then for a group of 15 generators as modules. Figure 5 indicates the generated voltage to the amount of water consumer per minute foe singe generator. Figure 6 indicates the generated voltage with respect to water flow when group of generators are connected together for charging purpose. Figure 7 explores the performance difference between the generated voltages when the generators are connected together.

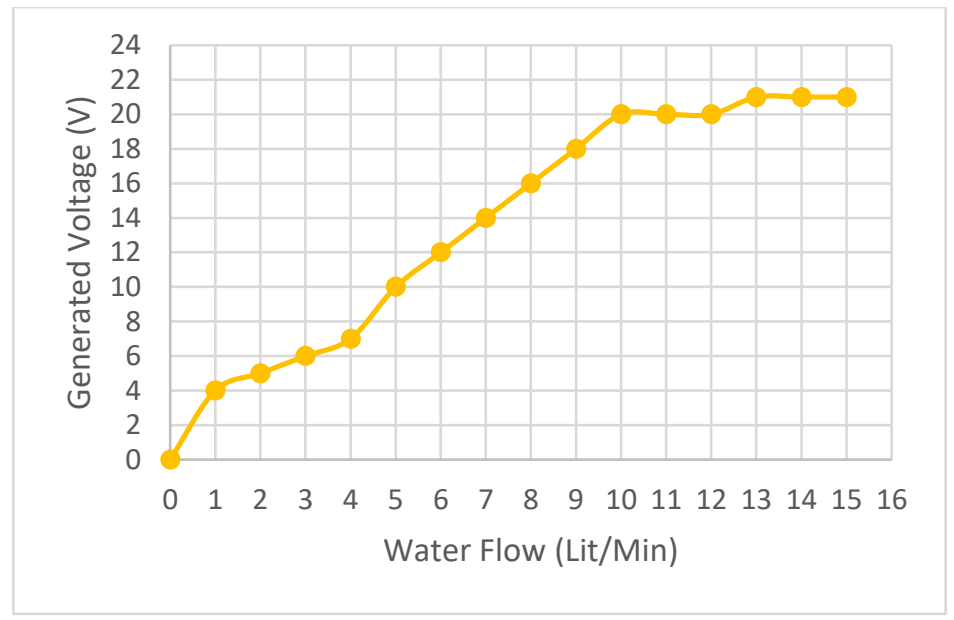

Figure 5. Generated Voltage Per Liter Of Water Flow.

ISSN: 2582-3051 
Journal of Electrical Engineering and Automation (EEA) (2020)

Vol.02/ No. 02

Pages: 92-101

https://www.irojournals.com/iroeea

DOI: https://doi.org/10.36548/jeea.2020.2.005

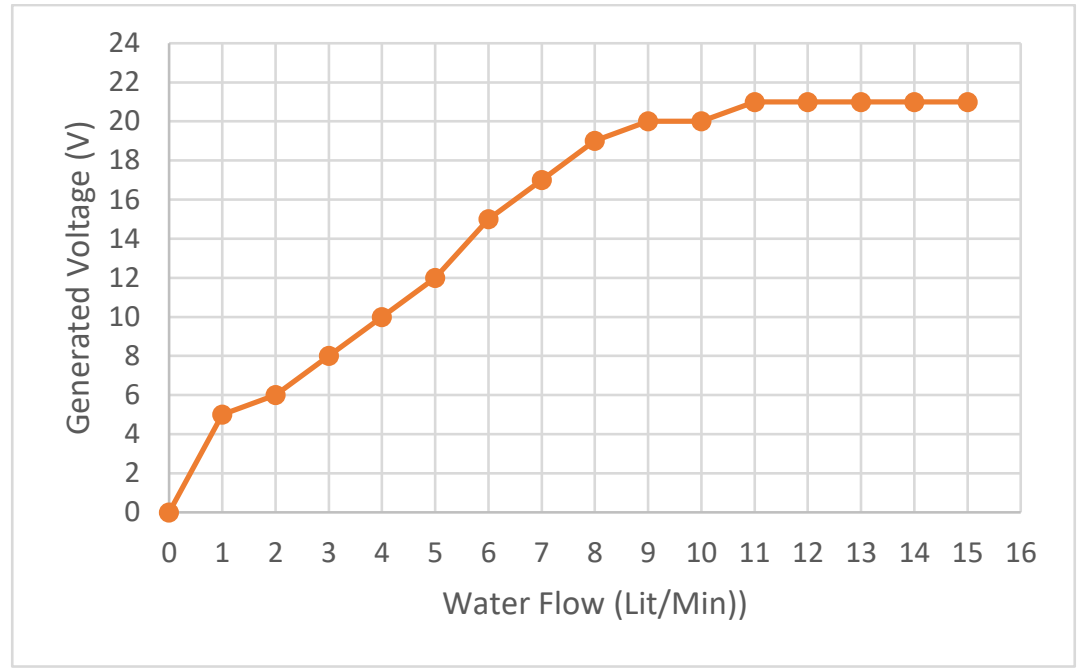

Figure 6. Generated Voltage Per Liter Of Water Flow In Group Of Generators.

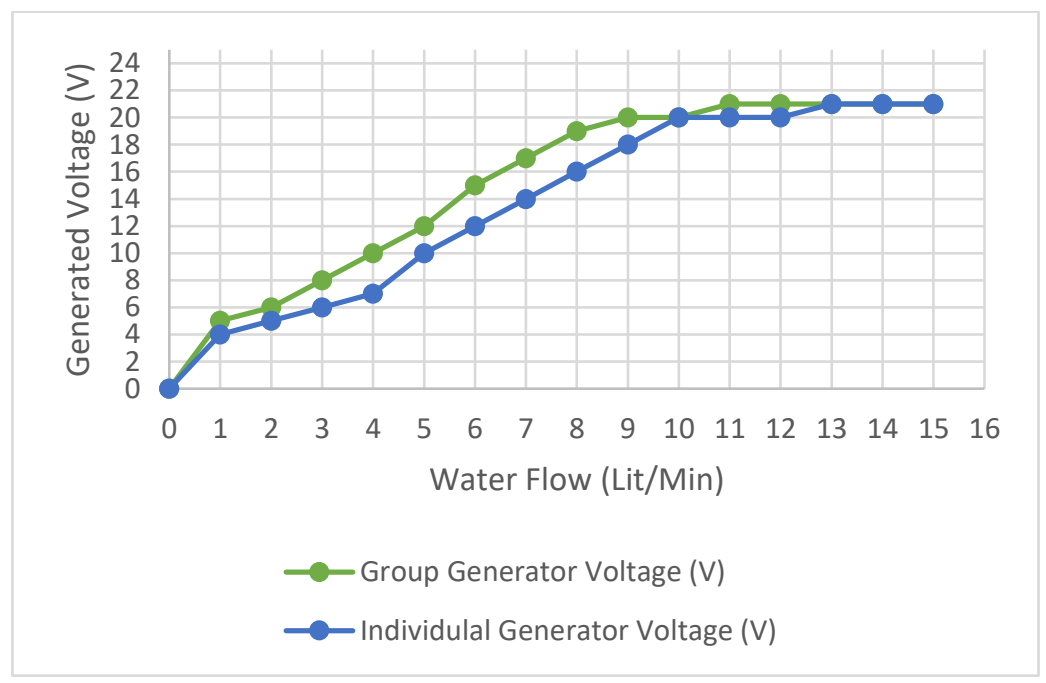

Figure 7. Performance Comparison between Individual and Group Generators.

The results are directly measured from the regulated output of the generator through arduino and the water flow readings are taken by a sensor fixed at the filling tank for measurement by arduino. The results indicates that the proposed model performs well when multiple generators are connected together for operations. A $12 \mathrm{~V}$ battery can be charged with this kind of model as it produces maximum of $21 \mathrm{~V}$ at a time. 
Journal of Electrical Engineering and Automation (EEA) (2020)

Vol.02/ No. 02

Pages: 92-101

https://www.irojournals.com/iroeea

DOI: https://doi.org/10.36548/jeea.2020.2.005

The flow rate for rotating the turbine efficiently requires 5 to 7 liters of water flow per minute. The proposed model can be combined with other renewable sources for making a hybrid structure to produce continuous and better output. As the pico generators are fixed inside the pipeline it requires special alteration to the pipeline. The alteration work can be eliminated when the pico turbine is fixed at the place of water flowing freely out from the pipeline when filling a tank.

\section{Conclusion}

The performance of multiple pico hydro generator model is analyzed for adding it to a hybrid station of power generation. The results are satisfied to make this design possible to add with a micro renewable generation source for sharing the load. The proposed model can generate high power and voltage when it is replaced with another range of generators. The design is also suitable for places where the power supply is difficult to attain. The model can be applied to special sensor monitoring devices located very near to water tanks and similar applications. The model is also suitable and sufficient for giving supply to wireless sensor networks connected in remote areas without traditional power supply.

\section{References}

[1] Jawahar, C. P., and Prawin Angel Michael. "A review on turbines for micro hydro power plant." Renewable and Sustainable Energy Reviews 72 (2017): 882-887.

[2] Chandramouli, A., and V. Sivachidambaranathan. "Extract Maximum Power from PV System Employing MPPT with FLC Controller." power 1: 4.

[3] Bhandari, Ramchandra, Lena Ganda Saptalena, and Wolfgang Kusch. "Sustainability assessment of a micro hydropower plant in Nepal." Energy, Sustainability and Society 8, no. 1 (2018): 3 .

[4] Tapia, A., P. Millán, and F. Gómez-Estern. "Integer programming to optimize Micro-Hydro Power Plants for generic river profiles." Renewable Energy 126 (2018): 905-914.

[5] Chen, Joy Iong Zong. "Computational offloading for performance improvement and energy saving in mobile devices."

[6] Salhi, Issam, Abdellatif Belattar, and Said Doubabi. "Takagi-Sugeno fuzzy modeling for threephase micro hydropower plant prototype." International Journal of Hydrogen Energy 42, no. 28 (2017): 17782-17792.

[7] Cavazzini, Giovanna, Alberto Santolin, Giorgio Pavesi, and Guido Ardizzon. "Accurate estimation model for small and micro hydropower plants costs in hybrid energy systems modelling." Energy 103 (2016): 746-757. 
Journal of Electrical Engineering and Automation (EEA) (2020)

Vol.02/ No. 02

Pages: 92-101

https://www.irojournals.com/iroeea

DOI: https://doi.org/10.36548/jeea.2020.2.005

[8] Raj, Jennifer S. "Machine Learning Based Resourceful Clustering With Load Optimization for Wireless Sensor Networks." Journal of Ubiquitous Computing and Communication Technologies (UCCT) 2, no. 01 (2020): 29-38.

[9] Saini, R. P., S. K. Singal, and Imtiyaz Ali. "Development of Modified Pump Used as Turbine in Micro Hydro Plants." In Rural Technology Development and Delivery, pp. 301-308. Springer, Singapore, 2019.

[10] Ali, Asad, Muftooh Ur Rehman Siddiqi, Riaz Muhammad, M. Suleman, and Nasim Ullah. "Design and implementation of an electromechanical control system for micro-hydropower plants." Electrical Engineering (2020): 1-8.

[11] Smys, S., and Haoxiang Wang. "Enhanced wireless power transfer system for implantable medical devices."

[12] Velazhagan, P., A. Ramesh Babu, M. D. Vijayakumar, and GT Sundar Rajan. "Prospect of Pico-Hydro Electric Power Generation Scheme by Using Consuming Water Distributed to Multi-storage Building." In Microelectronics, Electromagnetics and Telecommunications, pp. 213-221. Springer, Singapore, 2019.

[13] Pali, Bahadur Singh, and Shelly Vadhera. "A novel solar photovoltaic system with pumpedwater storage for continuous power at constant voltage." Energy conversion and management 181 (2019): 133-142.

[14] Haoxiang, Wang, and S. Smys. "Soft Computing Strategies for Optimized Route Selection in Wireless Sensor Network." Journal of Soft Computing Paradigm (JSCP) 2, no. 01 (2020): 112.

[15] Safdar, Ibadullah, Sara Sultan, Hamza Ahmad Raza, Muhammad Umer, and Majid Ali. "Empirical analysis of turbine and generator efficiency of a pico hydro system." Sustainable Energy Technologies and Assessments 37 (2020): 100605.

\section{Authors Biography}

Dr. P. Karrupusamy working as a Professor and Head in Department of Electrical and Electronics Engineering at Shree Venkateshwara Hi-Tech Engineering College, Erode. In 2017, He had completed doctorate in Anna University, Chennai and in 2007, he had completed his post graduate Power Electronicsand Drives in Government College of Technology, Coimbatore, India. He has more than 10 years of teaching experience. He has published more than 40 papers in national and international journals and conferences. He has acted as conference chair in IEEE international conferences and Guest editor in reputed journals. His research area includes Modeling of PV arrays, Adaptive Neuro-Fuzzy Model for Grid Connected Photovoltaic System with Multilevel Inverter. 